\title{
FRECUENCIA DE Toxoplasma gondii EN GATOS DE LIMA METROPOLITANA Y CONCORDANCIA ENTRE LAS TÉCNICAS DE INMUNOFLUORESCENCIA INDIRECTA Y HEMAGLUTINACIÓN INDIRECTA
}

\author{
Frequency of Toxoplasma Gondi in Cats in Metopolitan Lima and \\ CONCORDANCE BETWEEN INDIRECT IMMUNOFLUORESCENCE AND INDIRECT \\ Haemaglutination Techniques
}

\author{
Luis Cerro T. ${ }^{1}$, Amanda Chávez V. ${ }^{1,2}$, Eva Casas A. ${ }^{1}$, Francisco Suárez A. ${ }^{3}$ y Alicia \\ Rubio V. ${ }^{1}$
}

\section{Resumen}

\begin{abstract}
El objetivo del presente trabajo fue determinar la frecuencia de anticuerpos contra Toxoplasma gondii en Lima Metropolitana, así como estimar el grado de concordancia entre las técnicas de diagnóstico de Inmunofluorescencia Indirecta (IFI) y Hemaglutinación Indirecta (HAI). Se evaluó 178 muestras de sueros de gatos colectadas en varios distritos de Lima Metropolitana. Los resultados mostraron una frecuencia de serorreactores a $T$. gondii de $11.2 \pm 4.6 \%$ (HAI) y $17.9 \pm 5.6 \%$ (IFI), sin haber diferencia estadística por efecto del sexo y el grupo etáreo del gato. El valor de Kappa (K) de 0.73 indica una grado de concordancia sustancial entre ambas pruebas, mostrando que las pruebas pueden ser reemplazadas mutuamente.
\end{abstract}

Palabras clave: HAI, IFI, felinos domésticos, toxoplasmosis, Lima

\section{AbSTRACT}

The aim of the present work was to estimate the frequency of antibodies antiToxoplasma gondii in cats of Lima city, and to determine the rate of concordance between the Indirect Immunofluorescence (IFI) and Indirect Haemaglutination (HAI) assays. A total of 178 cat serum samples were collected in veterinary clinics of varios districts of Lima. The results showed $11.2 \pm 4.6 \%$ (HAI) and $17.9 \pm 5.6 \%$ (IFI) positive serums to $T$. gondii, and without statiscal differences due to sex and age group. The Kappa (K) value was 0.73 indicating a substantial concordance between the two assays indicating that both assays can be reciprocally replaced.

Key words: HAI, IFI, domestic cat, toxoplasmosis, Lima

\footnotetext{
${ }^{1}$ Laboratorio de Microbiología y Parasitología Veterinaria, ${ }^{3}$ Laboratorio de Medicina Veterinaria Preventiva, Facultad de Medicina Veterinaria, Universidad Nacional Mayor de San Marcos, Lima

${ }^{2}$ E-mail: achavezvg@gmail.com
} 


\section{INTRODUCCIÓN}

La toxoplasmosis es producida por el protozoario Toxoplasma gondii. Se le considera una enfermedad cosmopolita y afecta tanto a poblaciones humanas como a más de 300 especies de mamíferos y 30 especies de aves domésticas y silvestres (Rojas, 2003). La transmisión de la infección está relacionada con la presencia de felinos como hospedero definitivo y todos los animales de sangre caliente como hospederos intermediarios. Estos últimos albergan quistes tisulares latentes de por vida, completándose el ciclo cuando se tornan presas de los felinos (Soulsby, 1987).

Esta parasitosis es importante en ovinos y caprinos, debido a que puede producir mortalidad embrionaria, abortos, nonatos o crías débiles, con una mortalidad perinatal que puede 1 legar a 50\% (Acha y Szyfres, 2003). En humanos destaca la toxoplasmosis adquirida, que pasa desapercibida tanto para el paciente como para el clínico, donde la tercera parte de la humanidad ha sido expuesta a este parásito en algun momento de su vida. No causa alteraciones serias en la mayoría de las personas adultas; sin embargo, puede causar ceguera y retardo mental en niños con toxoplasmosis congénita relacionada con problemas oculares y serios problemas en individuos inmunocomprometidos (Hill y Dubey, 2002). Estudios realizados en el Perú demostraron que la toxoplasmosis es causante del $80 \%$ de los casos de uveítis parasitaria presentados en el Instituto Nacional de Oftalmología - INO (García, 2002).

Por sus características epidemiológicas, la región de la selva peruana posee la mayor prevalencia de reactores humanos a la toxoplasmosis, seguida de la Costa y, con menor frecuencia, la Sierra. La prevalencia de toxoplasmosis en 1986 fue de 75 a 85\% en diversas comunidades de la Selva Central, pudiendo ser considerada como una de las más altas tasas de prevalencias del mundo (INEI, 1994). Además, en las zonas ga- naderas del Perú se reportan tasas de seroreactores a $T$. gondii de $39 \%$ en borregas (Rojas, 2003) y 32\% en llamas (Gómez et al., 2003).

Los felinos desempeñan un papel fundamental en la epidemiología de la toxoplasmosis por ser los hospederos definitivos del $T$. gondii y los únicos animales donde se realiza la fase sexual del ciclo de vida eliminando los ooquistes infectantes (Pacheco et al., 2003). Estudios de seropositividad en gatos en diversos países muestran una prervalencia de 64\% (Soulsby, 1987).

La prueba de hemaglutinación indirecta (HAI) se usa como prueba de rutina clínica en hospitales veterinarios por su nivel de sesnsibilidad y fácil uso; sin embargo, no es muy específica, ya que presenta reacciones cruzadas con otros parásitos (Blood y Radostits, 1992). Por otro lado, la técnica de inmunofluorescencia indirecta (IFI) requiere equipo sofisticado, pero tiene una alta sensibilidad (99\%) y especificidad (100\%) (Ovalle et al., 2000).

Debido al rol del felino en el ciclo del parásito y en consideración a los escasos estudios de prevalencia en la capital peruana, se planteó el presente estudio a fin de estimar la frecuencia de $T$. gondii en gatos en Lima Metropolitana, así como para estimar el grado de concordancia entre las técnicas de diagnóstico más utilizadas en el medio.

\section{Materiales y Métodos}

\section{Características del Estudio}

Se trabajó con muestras de sangre de gatos domésticos obtenidas en consultorios veterinarios ubicados en varios distritos de Lima Metropolitana durante los meses de mayo del 2006 hasta junio de 2007.

Para el cálculo del tamaño muestral, y debido a la ausencia de estudios previos, se 
colectó una muestra inicial en 30 animales resultando en una prevalencia previa de $13 \%$ para T. gondii. Con este valor y mediante la aproximación normal a la binomial, se calculó un tamaño de muestra para estimar la prevalencia de T. gondii correspondiente a 178 felinos.

\section{Colección y Análisis de las Muestras}

Las muestras de sangre se obtuvieron mediante la punción directa de la vena yugular, usando vacutainers y agujas N. ${ }^{\circ} 23$ x 1 ". Las muestras fueron centrifugadas y los sueros resultantes se conservaron en congelación a $-20{ }^{\circ} \mathrm{C}$ hasta su procesamiento.

Los anticuerpos contra $T$. gondii se determinaron mediante el uso de dos pruebas: la Inmunofluorescencia Indirecta (IFI), técnica de alta sensibilidad y especificidad que detecta la presencia de anticuerpos ( $\operatorname{IgG}$ ), y donde la positividad del suero se considera al observarse fluorescencia completa del taquizoíto, mientras que en la muestra negativa no se aprecia tal fluorescencia o solo se hace en forma parcial (apical) o incompleta; y la prueba de Hemaglutinacion Indirecta (HAI), a través del kit comercial Toxotest-HAI (Wiener Lab, 2000), que detecta anticuerpos (IgG, IgM) contra $T$. gondii y donde la lectura se interpreta como negativo cuando ocurre la presencia de un sedimento en forma de botón o anillo de bordes regulares, y positivo con la formación de una película o manto que cubre el $50 \%$ o más del fondo de los pocillos, equivalente a valores $\geq 1 / 16$ (punto de corte). Por otra parte, el kit ofrece la posibilidad de usar el 2-Mercaptoetanol (MO), reactivo que permite diferenciar la presencia de IgG o IgM, por lo que se podría indicar si estamos frente a una infección aguda o crónica

\section{Análisis de Datos}

Se estimó la frecuencia de animales reactores a toxoplasma por tipo de prueba, analizando las variables sexo y edad de los animales. Adicionalmente, se utilizó la prueba de Kappa para determinar el grado de con- cordancia entre los valores de las pruebas serológicas de IFI y HAI (González y Falcón, 1999).

\section{Resultados}

Las frecuencias de gatos domésticos serorreactores a $T$. gondii mediante las pruebas de HAI e IFI fueron de $11.2 \pm 4.6 \%$ $(20 / 178)$ y $17.9 \pm 5.6 \%(32 / 178)$, respectivamente. No se encontró diferencias estadísticas por sexo o grupos etáreos $(\mathrm{p}>0.05)$ (Cuadro 1).

Además, se obtuvo un valor de Kappa de 0.73 , que indica que la concordancia entre las dos pruebas es substancial, indicando que ambas técnicas pueden ser reemplazadas mutuamente.

\section{Discusión}

La frecuencia de anticuerpos contra $T$. gondii de $11.2 \pm 4.6 \%$ (HAI) y $17.9 \pm 5.6 \%$ (IFI) indica que los felinos estuvieron expuestos al parásito en algun momento de su vida, ya sea en la etapa pre o post natal. Estas frecuencias son inferiores a reportes en Chile (33\%, Ovalle et al., 2000) y España (32\%, Miró et al., 2004) con la técnica de IFI, y en Brasil (37\%, Pacheco et al., 2003) con la técnica de HAI. No obstante, un reporte en Jerusalén indica $16.8 \%$ de prevalencia con la técnica de ELISA (Deeb et al., 1985). Los resultados del presente estudio se encuentran dentro del tercio inferior de las prevalencias esperadas a nivel mundial, la cual varía en gatos entre 9 y $74.0 \%$ (Tenter et al., 2000).

La frecuencia de anticuerpos contra toxoplasma es muy variada en la población felina y está relacionada al tipo de población, comportamiento, hábitos alimenticios, costumbres de los dueños e infraestructura hídrica y sanitaria, entre otros (Tenter et al., 2000). Los animales de este estudio eran ga- 
Cuadro 1. Frecuencia de anticuerpos anti-Toxoplasma gondii en gatos de Lima Metropolitana mediante las técnicas de Inmunofluorescencia Indirecta (HAI) e Hemaglutinacion Indirecta (IFI), según edad y sexo (2007)

\begin{tabular}{|c|c|c|c|}
\hline Variables & Total & $\begin{array}{c}\text { HAI } \\
\% \pm \text { IC }\end{array}$ & $\begin{array}{c}\text { IFI } \\
\% \pm \mathrm{IC}^{1}\end{array}$ \\
\hline \multicolumn{4}{|l|}{ Edad (años) } \\
\hline $0.5 \mathrm{a}<1$ & 27 & $7.4 \pm 9.8$ & $7.4 \pm 9.8$ \\
\hline$>1$ a 7 & 123 & $11.3 \pm 5.6$ & $18.7 \pm 6.8$ \\
\hline$>7$ & 28 & $14.2 \pm 12.9$ & $25.0 \pm 16.0$ \\
\hline \multicolumn{4}{|l|}{ Sexo } \\
\hline Macho & 96 & $9.3 \pm 5.8$ & $14.5 \pm 7.0$ \\
\hline Hembra & 82 & $13.4 \pm 7.3$ & $21.9 \pm 8.9$ \\
\hline Total & 178 & $11.2 \pm 4.6$ & $17.9 \pm 5.6$ \\
\hline
\end{tabular}

tos con domicilio conocido y la mayoría recibía alimento casero, por lo que el porcentaje de serorreactores resultó inferior al hallado en la mayoría de poblaciones de gatos callejeros, como ocurrió en el estudio de Sogorb et al. (1972) en Sao Paulo, Brasil, donde obtuvieron reacciones de $51 \%$. Se menciona, además, que las seroprevalencias son usualmente mayores en felinos silvestres en comparación con felinos que residen en zonas urbanas.

La clasificación de la fase clínica de la enfermedad mediante la titulación de los sueros a través de HAI y la identificación de IgM con el empleo de 2-ME mostró que el $60 \%$ de los animales seropositivos presentaban solo IgG; es decir, que se tratarían de casos crónicos en base a infecciones antiguas. Por otro lado, el $40 \%$ de los gatos seropositivos se encontraban en la fase aguda; hecho demostrado al usar 2-ME y observar la disminución de los títulos de al menos dos diluciones comparados con los mismos sueros sin tratar con 2-ME (Wiener Lab, 2000). Asimismo, se conoce que en la etapa aguda los felinos pueden eliminar millones de ooquistes en un solo día y que bajo condiciones de humedad y temperatura adecuada estos pueden sobrevivir en el medio ambiente por más de un año (Green, 2000).

Las frecuencias de anticuerpos anti- $T$. gondii se incrementaban con la edad, aunque estos valores no fueron estadísticamente significativos. Resultados similares han sido reportados por Jackson et al. (1987), llegando a demostrarse la edad como factor predisponente en otros estudios (Dubey et al., 1995). El sexo no fue una variable predisponente para la presentación de anticuerpos anti- $T$. gondii en este y otros estudios (Ovalle et al., 2000), pero un reporte en España menciona una seroprevalencia significantemente mayor en machos que en hembras adjudicando la diferencia a los hábitos territoriales de los machos (Smith et al., 1992).

La concordancia encontrada entre las técnicas de HAI e IFI (Kappa de 0.73) y una significancia estadística $(p<0.05)$ con la prueba de Mc Nemar corrobora los resultados de 
otros estudios en otras especies. Ishizuka et al. (1986) y Germani y Pacheco (2002) compararon estas técnicas para anticuerpos anti$T$. gondii en porcinos obteniendo índices de kappa de 0.69 y 0.46 , respectivamente y un Mc Nemar con diferencia significativa. Recientemente en Perú se hizo un estudio en ovinos donde se obtuvo un valor de kappa de 0.24 (Huerta, 2005). Estos valores evidencian que estas dos técnicas no pueden reemplazarse mutuamente.

Se ha comprobado una correlación positiva y significativa entre los títulos de anticuerpos del hombre con los títulos de los felinos, posiblemente debido a que el hombre comparte las mismas vías de transmisión que el felino y la presencia de los gatos es probablemente la causa de esa correlación positiva (García et al., 1999). La importancia de la toxoplasmosis en términos de salud pública se debe a que esta zoonosis representa una causa importante de alteraciones neonatales como lesiones oculares, microcefalia, hidrocefalia, calcificaciones cerebrales, alteraciones psicomotoras y retardo mental; y en pacientes inmunocomprometidos, como en los casos de SIDA, donde se puede presentar una encefalitis toxoplásmica (Amato Neto et al., 1982).

\section{Conclusiones}

- Se encontró una frecuencia moderada de anticuerpos anti-Toxoplasma gondii en gatos en Lima Metropolitana [11.2 \pm $4.6 \%$ con la técnica de Inmunofluorescencia Indirecta (HAI) y $17.9 \pm 5.6 \%$ con la técnica de Hemaglutinacion Indirecta (IFI)].

- No se observaron diferencias estadísticas entre los reactores a toxoplasma para las variables sexo y edad.

- El grado de asociación encontrado entre las técnicas de HAI e IFI para detectar anticuerpos anti-Toxoplasma gondii en gatos fue substancial $(K=0.73)$, determinándose que que dichas pruebas son reemplazables entre sí.

\section{Literatura Citada}

1. Acha P, Szyfres B. 2003. Zoonosis y enfermedades transmisibles comunes al hombre y a los animales. $3^{\mathrm{a}} \mathrm{ed}$. Vol III. Parasitosis. Publicación Científica y Técnica $\mathrm{N}^{\circ}$ 580. OPS. $413 \mathrm{p}$.

2. Amato Neto V, Campos $R$, Baruzzi R, Duarte M. 1982. Toxoplasmose. São Paulo: Sarvier $155 \mathrm{p}$.

3. Blood D, Radostits O. 1992. Medicina veterinaria. $7^{\text {a }}$ ed. España: Ed. Interamericana. $1598 \mathrm{p}$.

4. Deeb J, Sufan M, Di Giacomo R. 1985. Toxoplasma gondii infection of cats in Beirut, Lebanon. Am J Trop Med Hyg 88: 301-306.

5. Dubey J, Lappin M, Thulliez P. 1995. Long term antibody responses of cat fed Toxoplasma gondii tissue cysts. J Parasitol 81: 887-893.

6. García J, Garcia L, Navarro T, Ogawa L, Claret R. 1999. Soro-epidemiologia da toxoplasmose em gatos e cães de propriedades rurais do Município de Jaguapitã, Estado do Paraná, Brasil. Ciênc Rural 29(1): 99-104.

7. García M. 2002. Estudio de las zoonosis parasitarias de localización ocular en el instituto de Oftalmología (INO) durante el período 1985-1999. Tesis de Médico Veterinario. Lima: Facultad de Medicina Veterinaria, Univ. Nacional Mayor de San Marcos. 65 p.

8. Germani C, Pacheco F. 2002. Comparação entre os testes de inmunofluorescencia indirecta e hemaglutinacão indirecta para detecção de anticorpos anti Toxoplasma gondii em soros de suínos. Acta Scientiae Veterinariae 30(3): 185-189.

9. Gómez F, Chávez A, Casas E, Serrano E, Cárdenas O. 2003. Determinación de la seroprevalencia de toxo- 
plasmosis en alpacas y llamas en la Estación Experimental INIA-Puno. Rev Inv Vet, Perú 14: 49-53.

10. González A, Falcón N. 1999. Análisis de datos en Medicina Veterinaria. Lima: FMV. Púb Tec $\mathrm{N}^{\circ}$ 49. p 49-57.

11. Green C. 2000. Enfermedades infecciosas en perros y gatos. $2^{\mathrm{a}}$ ed. México: Interamericana. $1014 \mathrm{p}$.

12. Hill D, Dubey J. 2002. Toxoplasma gondii: transmission, diagnosis and prevention. Clin Microbiol Infec 8: 634640.

13. Huerta O. 2005. Concordancia entre las pruebas de Hemaglutinacion Indirecta e Inmunofluorescencia Indirecta para determinar la prevalencia de Toxoplasma gondii en ovinos. Tesis de Médico Veterinario. Lima: Facultad de Medicina Veterinaria, Univ. Nacional Mayor de San Marcos. $54 \mathrm{p}$.

14. [INEI] Instituto Nacional de Estadística e Informática. 1994. III Censo Nacional Agropecuario (CENAGRO). Banco de datos estadísticos. [Internet]. Disponible en: htpp: www.inei.gob.pe.

15. Ishizuka M, D'Angelino J, Souza J. 1986. Toxoplasmose suína. II. Estudo comparativo das provas imunofluorescência indireta e hemaglutinação, para a avaliação de anticorpos anti-toxoplasma em soros suínos. B Ofic Sanit Panam 100: 524-530.

16. Jackson M, Hutchison W, Siim J. 1987. Prevalence of Toxoplasma gondii in meat animals, cats and dogs in central Scotland. Br Vet J 143: 159-165.

17. Miró G, Montoya A, Jiménez S, Frisuelos C, Mateo M. 2004. Prevalence of antibodies to Toxoplasma gondii and intestinal parasites in stray, farm and household cats in Spain. Vet Parasitol 126: 249-255.

18. Ovalle F, García A, Thibauth A. 2000. Frecuencia de anticuerpos anti Toxoplasma gondii en gatos de la ciudad de Valdivia, Chile. Bol Chi. Parasitol 55(3-4): 94-99.

19. Pacheco A, Santos N, Tarnoswki A, Beck C, Díaz R, Germani C. 2003. Anticorpos para Toxoplasma gondii em soro de gatos internados no Hospital de Clínicas Veterinárias da UFRGS, Porto Alegre, RS, Brasil, detectados através da técnica de hemaglutinação indireta. Acta Scientiae Veterinariae 31(2): 89- 92.

20. Rojas M. 2003. Nosoparasitosis de perros y gatos peruanos. Lima: Ed. Martegraf. $146 \mathrm{p}$.

21. Smith K, Zimmerman J, Patton S, Beran G, Hill H. 1992. The epidemiology of toxoplasmosis on Iowa swine farms with an emphasis on the roles of free-living mammals. Vet Parasitol 42: 199-211.

22. Sogorb F, Jamra L, Guimarães E, Deane M. 1972. Toxoplasmose espontânea em animais domésticos e silvestres, em São Paulo. Rev Inst Med Trop S Paulo 14/15(5): 514520.

23. Soulsby E. 1987. Parasitología y enfermedades parasitarias. $7^{\mathrm{a}}$ ed. México: Ed. Interamericana. $823 \mathrm{p}$.

24. Tenter A, Heckeroth A, Weiss L. 2000. Toxoplasma gondii: from animals to humans. Int J Parasitol 30: 1217-1258.

25. Wiener Lab. 2000. Toxotest HAI. [Internet], [13 octubre 2007]. Disponible en: http://www.wienernet.com.ar/sp/ vademecum/toxotest_hai.pdf 